\title{
Screening of School Children for Operable Congenital Heart Diseases in Dhaka city
}

\author{
SJ Urmi ${ }^{1}$, MM Rahman $^{2}$, M Alimuzzaman ${ }^{3}$ \\ ${ }^{1}$ Department of Obstetrics \& Gynaecology, Shaheed Suhrawardy Medical College \& Hospital, Dhaka, \\ ${ }^{2}$ Department of Cardiac Surgery, Bangabandhu Sheikh Mujib Medical University, Dhaka, \\ ${ }^{3}$ Department of Cardiac Surgery, Lab Aid Cardiac Hospital, Dhaka
}

Key words: Congenical heart disease.

\begin{abstract}
:
Backgrond: As there is no basic epidemiological study of congenital heart disease in Bangladesh, so this work was designed by the study group and was supported by Bangladesh Medical Research Council.

Methods: Cross-sectional study of school going children, age ranging from 6-16 of Dhaka City were physically examined in addition to history and when required special investigation such as echocardiography was done.
\end{abstract}

Results: A random sample of 5900 school-going children in the age group of 6-16 years from public and private schools of Dhaka city were screened for the prevalence of operable congenital heart diseases (CHD) during a period of 1 year. Congenital heart diseases were diagnosed, preliminary on the basis of clinical history and/or clinical examination, then confirmed by supportive investigations, such as echocardiography. Out of examined sample, 112 were found suffering from CHD, giving an overall prevalence of 19.0/1000 (16.2/1000 in boys and 22.2/1000 in girls), far greater than that of the figures recorded in available literatures for other countries. The prevalence rate was higher in girls than that of boys in the present study, which may indicate a negligence of caring towards female children in the family. In consistent, children from lower income group had a higher prevalence rate compared to their middle income group counterparts (Low income group vs middle income group: 24.5/1000 vs 13.0/1000).Poor income group had less antenatal checkup which could detect congenital heart disease earlier. Fifty three children were found to be suffering from definite operable CHD giving a prevalence of 8.98 per thousand, where, again, girls were the main victims (girls vs boys: 12.0/1000 vs 6.4/1000). Atrial septal defect was the commonest lesion $7.6 \%)$ with a prevalence of 76 per thousand followed by ventricular septal defect (4.7 \%) with a prevalence of 47 per thousand. Five (9.4\%) cases had a family history of CHD. History of rheumatic fever and/or rheumatic heart disease were found to have a significant prevalence among cases with CHD (11.9\%) as compared to children without CHD (0.9\%).

Conclusion: The findings of the present survey suggest the need of more frequent antenatal checkup especially in low income group large scale screening of apparently healthy children for CHD, and family members of those suffering from CHD, and that special attention be paid to the occurrence of rheumatic fever/rheumatic heart disease in cases of CHD.

(Cardiovasc.j. 2010; 3(1) : 22-25)

\section{Introduction:}

Congenital heart disease (CHD) is a general term used to describe abnormalities of the heart or great vessels that are present from birth. Going by figures quoted in Western countries it has been generally accepted that approximately $1 \%$ of babies are born with congenital cardiac malformations in case of full-term births. ${ }^{1}$ The frequency may be more higher in our children as it has been suggested in the available literatures. ${ }^{2,3,4}$ Although, some of them produce manifestations soon after birth, others do not necessarily become evident until late childhood or even as late as adulthood (eg. Atrial septal defect [ASD], coarctation of aorta etc.). The number of adults with CHD is increasing rapidly as a direct result of advances in diagnostic methods and in the medical with surgical care of the infants. 
However, now with modern cardiac surgery, more than $85 \%$ of the estimated 25,000 infants born annually with CHD are likely to reach adulthood. ${ }^{5}$ Most of these survivors have malformations that can be corrected by currently available surgical techniques. Thus, out of 10 babies of the 1000 born with CHD, at least 8 can be expected to survive and to live normal life. Projecting these Western figures on our population, for a population of 140 millions, there would be a chance of approximately 1.4 millions people who would have been born with CHD. Under the current situation of cardiac surgery in our country, it is possible to offer palliative/corrective cardiac surgery to these patients in order to decrease children morbidity and mortality related to CHD.

Fetal heart screening program in the obstetric population is also supported by other authors 6 justified. It defines a high-risk group for karyotyping, allows planning of delivery in a tertiary center or the choice of terminating the pregnancy for the parents and appears to have a positive cost-benefit ratio. ${ }^{6}$

In ideal circumstances, the vast majority of serious heart malformations could be detected before 20 weeks' gestation. $^{7}$

In general, the later in the mid-trimester that scanning is performed the more successful will be the detection of abnormalities, partly because scanning becomes easier and partly because some lesions become more evident as pregnancy advances. However, later detection of malformations will limit the options for interrupting the pregnancy or make it much more difficult both emotionally for the parents and technically for the obstetrician. Thus, the ideal policy would be a universal anatomical scan at a compromise time of between 18-20 weeks' gestation. Thus early detection can help us to treat the disease at earliest possible time. ${ }^{7}$

Despite the fact that almost all of the common CHD are easy to detect by means of simple and widely available measurement device, majority of the patients/parents remain unaware of their condition during the early stages. Most children are free of symptoms for many years and the condition is often detected at routine clinical examination or at examination for some unconnected reasons. Even those with serious malformations are often described as the wildest member of the family by parents who find it difficult to believe or to accept that there is anything wrong with their child's heart. In most cases, an accurate diagnosis can be made at the bedside simply by careful clinical examination supplemented by simple ancillary tests, such as X-rays, ECG and echocardiography. In order to decrease the late fate of CHD, immense strides have been made in the diagnosis and therapy of congenital heart defects, allowing extended survival for many children. ${ }^{6,7}$ Most forms are now amenable to surgical repair with good results. Timely cardiac surgery promises almost normal longevity to these children.

Thus, there is a clear need for community based survey to determine the prevalence of CHD for a particular community or segment in order to make an exact appraisal of the magnitude of the problem. The present communication is aimed as first step in this direction. Then, the present study is designed to determine the prevalence of CHD in school children of Dhaka city.

\section{Materials \& methods:}

A cross-sectional study was carried out on 1656 school children aged 6-16 years to find the prevalence rate of CHD among the apparently healthy urban school children. The selection of subjects was on the basis of random sampling from the present students (on the day of examination) of ten public schools of Dhaka city. These schools usually cater to the educational needs of the lower and middle class families of this city. As it has been predicted that CHD is prevalent among the underprivileged population, so school-going children from affluent families were excluded from the present study. The social status of the family was assessed by the occupation of the parents/ guardians, monthly income of the family, family members, type of residence etc. The subjects were all apparently normal and healthy school going children. The age of the subject was determined from their date of birth recorded in the school register, and then it was rounded off to the nearest whole number. Standing height and weight were measured by standard anthropometric rod and weighing machine, respectively.

An interview sheet was filled up by direct interview with the students and/or guardians, 
when necessary, on a pre-appointed date and time. History of rheumatic fever, recurrent respiratory tract infection and other complaints related to CHD were asked and recorded, in addition to socioeconomic status. A leaflet was printed, in simple Bengali language, explaining the aims and objectives of this work to motivate the parents. The benefits of such work was emphasized through lectures and demonstrations in order to ensure more participation. Assurance was given to the parents/guardians that, if desired, the findings could be kept confidential.

A complete physical examination was carried by specialists. The children, with suspected CHD, was advised to report for further examination and necessary investigations in National Institute of Cardiovascular Diseases (NICVD) to confirm the diagnosis, and then treatment. In reported cases, appropriate surgical intervention was carried out after confirmation of the diagnosis.

\section{Results \& Discussions:}

A total number of 6017 school-going children in the age group of 6-16 years were, primarily, screened for the determination of the prevalence rate of operable CHD. But, during final processing of the data, the record of 117 was not considered as most of those had incomplete information. Thus, finally, 5900 school children were, where boys were 3150 and girls were 2750 , assessed.

Table-I

Study population

\begin{tabular}{lcccc}
\hline Age & \multicolumn{2}{c}{ Male $(\mathrm{n}=3150)$} & \multicolumn{2}{c}{ Female $(\mathrm{n}=2750)$} \\
Groups & $\begin{array}{c}\text { Low } \\
\text { Income } \\
\text { Group }\end{array}$ & $\begin{array}{c}\text { Middle } \\
\text { Income } \\
\text { Group }\end{array}$ & $\begin{array}{c}\text { Low } \\
\text { Income } \\
\text { Group }\end{array}$ & $\begin{array}{c}\text { Middle } \\
\text { Income } \\
\text { Group }\end{array}$ \\
\hline $6-8$ & 380 & 401 & 369 & 410 \\
$9-11$ & 391 & 399 & 417 & 309 \\
$12-14$ & 297 & 422 & 299 & 237 \\
$15-16$ & 481 & 379 & 390 & 319 \\
\hline Total & 1549 & 1601 & 1475 & 1275 \\
\hline
\end{tabular}

Table I shows the distribution of the study population according to their sex and socioeconomic class in different age groups. Out of the examined sample, 112 were found to have CHD, giving prevalence rate of 19.98/1000 (Table no. II). The prevalence rate was clearly higher than other studies carried out in different countries. ${ }^{1,10-15}$ Although, going by figures quoted in Western countries it has been generally accepted that approximately 10/1000 of babies are born with CHD in case of full-term births, ${ }^{1}$ others reported a relatively lower prevalence from different countries. ${ }^{10-15}$ From India, it has been reported a prevalence of CHD among their school children of only 2.25/1000. ${ }^{10}$ But, in one community based study, the investigators reported a higher prevalence rate of CHD among Delhi children of 4.2/1000. ${ }^{15}$ In South Africa, the prevalence of CHD among school children accounted for only 1.01/1000 .13

The prevalence of CHD, diagnosed preliminary by history and clinical examination in the present study, was found to be significantly higher in female $(54 \%)$ than in male children $(46 \%)(\mathrm{p}<0.05)$ (Table no. II ). At the end of appropriate investigations for confirmation of the diagnosis, still the girls were the major victims (Table no. III). In consistent with the present finding, Thakur et al. 10 also observed a higher prevalence of CHD among female school-going children in the age group of 515 years in Shimla hills, India. In contrast, there was a male predominance of CHD among school children from Alexandria, Egypt. ${ }^{13}$ The observed high prevalence of operable CHD among our school-going girls may indicate a negligence of raring up of our female babies than that of their male counterparts. Actually, in most of our families, boys get more care/ importance than that of girls in terms of their feeding, academic education, health check up irrespective of the social status of family in the society.

\section{Table-II}

School-going children having cardiac problems diagnosed by history and clinical examination

\begin{tabular}{|c|c|c|c|c|}
\hline \multirow[t]{2}{*}{$\begin{array}{l}\text { Age } \\
\text { Groups }\end{array}$} & \multicolumn{2}{|c|}{$\begin{array}{c}\text { Male } \\
(\mathrm{n}=51,45.53 \%)\end{array}$} & \multicolumn{2}{|c|}{$\begin{array}{c}\text { Female } \\
(\mathrm{n}=61,54.46 \%)\end{array}$} \\
\hline & $\begin{array}{l}\text { Low } \\
\text { Income } \\
\text { Group }\end{array}$ & $\begin{array}{l}\text { Middle } \\
\text { Income } \\
\text { Group }\end{array}$ & $\begin{array}{l}\text { Low } \\
\text { Income } \\
\text { Group }\end{array}$ & $\begin{array}{l}\text { Middle } \\
\text { Income } \\
\text { Group }\end{array}$ \\
\hline $6-8$ & 9 & 3 & 11 & 4 \\
\hline $9-11$ & 13 & 7 & 16 & 8 \\
\hline $12-14$ & 7 & 5 & 9 & 3 \\
\hline $15-16$ & 10 & 3 & 11 & 5 \\
\hline $6-16$ & 39 (76.47\%) & $12(23.53 \%)$ & $47(77.05 \%)$ & $14(22.95 \%)$ \\
\hline
\end{tabular}


Again, among 51 male students with CHD, 39 (76.47\%) were from low-income group. Similar trend was seen for female students, 47 (77.05\%) of the girls with CHD were from low income group (Table no. II). Out of 3024 school going children, of low income families, screened for CHD, a total of 86 (prevalence was 28.43/1000) children had CHD, on the other hand 26 (prevalence was 9.03/1000) children of middle income families had CHD. The high prevalence of CHD among school-going children of low income group (Table no. II \&). Out of 3024 school going children of low income families, screened for CHD, a total of 86 (prevalence was 28.43/1000) children had CHD, on the other hand 26 (prevalence was 9.03/1000) children of middle income families had CHD. The high prevalence of CHD among school-going children of low income group, irrespective of sex, indicates either ignorance or lack of health consciousness among theses group of population. Thus, the observed high prevalence rate of CHD among the school-going children, in the present study, may be due to inclusion of poor and under-privileged boys and girls.

\section{Table-III}

Common cardiac problems identified in children with $C H D$

\begin{tabular}{lccc}
\hline Diseases & Female & Male & Total \\
\hline $\begin{array}{l}\text { Atrial Septal } \\
\text { Defect (ASD) }\end{array}$ & 25 & 20 & 45 \\
$\begin{array}{l}\text { Ventricular Septal } \\
\text { Defect (VSD) }\end{array}$ & 15 & 13 & 28 \\
$\begin{array}{l}\text { Patent Ductus } \\
\text { Arteriosus (PDA) }\end{array}$ & 10 & 8 & 18 \\
$\begin{array}{l}\text { Tetrology of Fallot } \\
\text { (TOF) }\end{array}$ & 7 & 6 & 13 \\
$\begin{array}{l}\text { Coarctation of } \\
\text { aorta }\end{array}$ & 2 & 2 & 4 \\
Others & 2 & 2 & 4 \\
\hline Total & $61(54.5 \%)$ & $51(45.5 \%)$ & 112 \\
\hline
\end{tabular}

Atrial septal defect was the commonest lesion (40\%) with a prevalence of 7.6 per thousand followed by ventricular septal defect (25\%) with a prevalence of 4.7 per thousand (table no. III \&). Five (9.4\%) cases had a family history of CHD. History of rheumatic fever and/or rheumatic heart disease were found to have a significant prevalence among cases with CHD (11.9\%) as compared to children without CHD $(0.9 \%)(\mathrm{p}<0.05)$.
Therefore, the findings of the present survey suggest the need of large scale screening of apparently healthy children for CHD irrespective of family status, and family members of those suffering from CHD, and that special attention be paid to the occurrence of rheumatic fever/ rheumatic heart disease in cases of CHD.

\section{References:}

1. Davidson: Principles and Practice of Medicine. Ed. Edwards CRW, Bouchier IAD, Haslett C and Chilvers E; 17 th edition, ELBS with Churchil, Livingtone, 1995; P.

2. Haque SA, Majumder AAS, Chowdhury MS, Hossain MA, Haq SM and Rowshan AHM: Pattern of comgenital heart diseases at Dhaka Medical College Hospital, Dhaka: An echocardiographic analysis. J Dhaka Med Coll 1995; 491: 13-7.

3. Hussain M, Hossain M, Amin SK and Molla MR: Pattern of congenital heart diseases in Dhaka Shishu Hospital. Dhaka Shishu Hospital Journal 1992; 8: 42-46.

4. Talukder MQK: Identification of congenital heart diseases (CHD). Bangladesh Medical Journal (Khulna Branch) 1983; 16(2): 23-7.

5. Moller JH and Kaplan EL: Forty years of cardiac disease in children. Progress and problems. Minn Med 1991; 74: 26-8.

6. Rustico MA, Conoscenti G, Meir Y, Montesano M, Cattaneo A, MandruzzatoG:Fetal heart rate screening in low risk pregnancies. Ultrasound Obstet Gynecol. 1995; 6(5): 313-9

7. Linsey Allan: Antenatal diagnosis of heart disease. Heart 2000;83:367

8. Morris CD and Menashe VD: 25-year mortality after surgical repair of congenital heaart defect in childhood. JAMA; 1991, 266: 3447-51.

9. Perioff JK: Congenital heart disease in adults: A new cardio-vascular subspeciality. Circulation, 1991; 84: 1881-8.

10. Thakur JS, Negi PC, Ahluwalia SK, Sharma R and Bhardwaj R: Congenital heart disease among school children in Shimla hills. Indian Heart J 1995; 47(3): 232-7.

11. Subramanyan R, Joy J, Venugopalan P, Sapru A and al Khusaiby SM: Incidence and spectrum of congenital heart disease in Oman. Ann Trop Paediatr 2000; 20 (4): 337-49.

12. Shibata H, Matsuzaki T, Hayashi N, Morishima A and Saito T: Congenital heart disease in high school and college students. Jpn Heart J 1977; 18 (4): 457-67.

13. Bassili A, Mokhtar SA, Dabous NI, Zaher SR, Mokhtar $\mathrm{MM}$ and Zaki A: Congenita heart disease among school children in Alexandria, Egypt: an overview on prevalence and relative frequencies. J Trop Paediatr 2000; 46 (6): 357-9.

14. McLaren MJ, Lachman AS and JB: Prevalence of congenital heart disease in black schoolchildren of Soweto, Johannesburg. Br Heart J 1979,41 (5): 554-8.

15. Chandha SL, Singh N and Shukla DK: Epidemiological study of congenital heart disease. Indian $J$ Paediatr 2001; 68 (6): 507-9. 